\title{
THE PATTERN OF ANTIBIOTIC PRESCRIBING BY DENTAL PRACTITIONERS IN ZAGREB, CROATIA
}

\author{
Marina Perić1, Ivana Perković1, Martina Romić ${ }^{1}$, Paris Simeon², Jurica Matijević2 , Goranka Prpić Mehičić2 \\ Silvana Jukić Krmek \\ 'School of Dental Medicine, University of Zagreb, Zagreb, Croatia \\ ${ }^{2}$ Department of Endodontics and Restorative Dentistry, School of Dental Medicine, University of Zagreb, Zagreb, Croatia
}

\begin{abstract}
SUMMARY
Background: Bacterial resistance is considered a consequence of misuse or overuse of antibiotics. Dentistry significantly contributes to this increasing public health problem. The aim of this cross-sectional study was to examine the pattern of antibiotics prescribed by Croatian dentists in Zagreb area.

Methods: Out of 220 Doctors of Dental Medicine (DMDs) from Zagreb 110 responded to survey. Prior to the research an ethical approval was obtained. Participants were directly contacted. The questionnaire consisted of two parts: general data on DMDs and the part concerning indications, duration, type and dosage of antibiotic therapy. Data were processed using MS Excel and SPSS for Windows, Version 17.0. Statistical significance was tested by Fisher's exact test, chi-square test, Mann-Whitney U test and Spearman's rank correlation at the level of statistical significance $p<0.05$.

Results: During the period of two months, the doctors prescribed antibiotics to 1,500 patients, $690(46 \%)$ were men and $810(54 \%)$ women. The most often prescribed antibiotics were penicillin ( $72.5 \%$ of patients), represented mostly by amoxicillin in combination with clavulanic acid (57.6\%). The most common indication for the prescribed antibiotics was periapical or periodontal abscess (44\%). Definite clinical indication (71.2\%) was stated as the most common reason for antibiotic prescription. Antibiotic therapy usually lasted 7 days $(62.9 \%)$. The doctors prescribed daily doses of antibiotics according to the instructions for the use of specific drugs.

Conclusion: The examined subjects prescribe antibiotics according to the curriculum taught at the School of Dental Medicine for majority of types, doses and duration of the treatments, although antibiotics over-prescription in cases without medical indication was observed. The national guidelines on antibiotic regimens are required in order to reduce unnecessary antibiotic use.
\end{abstract}

Key words: doctors of dental medicine, antibiotics, diagnoses, doses of antibiotics, duration of therapy

Address for correspondence: S. Jukić Krmek, Department of Endodontics and Restorative Dentistry, School of Dental Medicine, University of Zagreb, Gundulićeva 5, 10000 Zagreb, Croatia. E-mail: jukic@sfzg.hr

\section{INTRODUCTION}

In dental practice antibiotics are used for the treatment of acute odontogenic (facial cellulitis, pericoronitis, lateral periodontal abscess, and necrotizing ulcerative gingivitis) and non-odontogenic infections (specific and non-specific) (1). Also, antibiotics in dentistry could be used for prophylaxis of focal infections (in patients at risk for infective endocarditis development, with compromised immune system, and with prosthetic joint of hip, knee or shoulder) as well as for the prophylaxis of local infection and its systemic spread (prevention of surgical wound infection) (2-5). Apart from the benefits of antibiotic administration such as shortening of infection periods and minimizing the risk of spread of infection to adjacent tissues or systemic involvement, serious side effects and complications implicate caution and strict indications for prescribing antibiotics (6). These side effects range from mild gastrointestinal disturbances to severe pseudomembranous colitis or even fatal anaphylactic shock (2). Besides the development of bacterial resistance, the consequences of misuse or overuse of antibiotics are considered an increasing problem of the public health (7). Since doctors of dental medicine prescribe between $7 \%$ and $11 \%$ of all conventional antibiotics (beta-lactams, macrolides, tetracyclines, clindamycin, metronidazole) (2), their contribution to the development of antimicrobial resistance might be significant (3). Incorrect dosage, prolonged duration of antibiotic therapy and use without indication (excessive use) are factors that can influence the development of antimicrobial resistance of microorganisms (6).

Indications for use of systemic antibiotics in dentistry are limited, since most dental and periodontal diseases are best managed by local intervention and oral hygiene measures. A critical approach to the use of antibiotics in the treatment of odontogenic infections dictates precisely defined criteria for the indication of antibiotic therapy. These are temperature rise, regional lymphadenitis, spreading infection, patient malaise and/or the patient with a specific medical condition (8). At least one of these conditions must exist to justify prescribing antibiotic therapy (9). However, the literature provides evidence of inappropriate prescribing practices by doctors of dental medicine due to a number of factors ranging from inadequate knowledge to social factors $(2,10,11)$.

In Croatia, according to the literature, comprehensive study on the pattern of use of antibiotics in dental practice has not been conducted yet. Therefore, a questionnaire survey was conducted to assess the pattern of antibiotics prescribing related to diagnosis, 
reason for prescribing, antibiotic type, dosage and duration of therapy by doctors of dental medicine.

\section{MATERIALS AND METHODS}

\section{Target Population}

The target sample comprised the doctors of dental medicine (DMD) employed in dental offices in the period between December 2010 and January 2011 in Zagreb area and their patients who were prescribed an antibiotic therapy. All the participating doctors were contacted personally several times.

\section{Type and Size of the Sample}

The examined sample comprised 556 DMDs from Zagreb area. The list of active dental practitioners was obtained from The Croatian Health Insurance Institute (CHII) and the research archive of the "Biometrics" agencies. DMDs were divided in two groups: teams within the public health care system - 382/556 $(68.7 \%)$, and private practice teams - 174/556 (31.3\%). Randomization was performed in both populations by MS Excel random number generator. In the second stage of the study, the selected doctors individually followed the patients under the antibiotic therapy during the above mentioned period. In order to achieve the statistically reliable results, the optimal number of examined doctors in the study was calculated from the total sample size, i.e. number of dentists working in Zagreb area (556) and it was determined to be 96 . When the usual response rate to the questionnaires $(50 \%)$ and average of $15 \%$ of incompletely filled questionnaires were taken into account, the calculated final number of participants was 220 . The number of valid questionnaires was 110. Data were entered into MS Excel database and statistically analysed using the Study Size Biometrics program (ver.2.0.4, Bertie Olofsson CreoStat, HB)

\section{Questionnaire}

A questionnaire was based on similar studies $(8,12)$ and it was divided into two parts. The first section included the data about doctors of dental medicine, and the second was a table filled in by participants over the period of two months. The first part of the questionnaire included gender, age, place of practice, year of graduation, certified specialty, whether the respondents in the last two years attended a seminar dealing with topics on prescribing antibiotics, the most commonly prescribed antibiotics, visits by representatives of pharmaceutical companies that produce antibiotics specific to dentistry, the total number of patients during the study period, the number of working days per week and the number of working hours per day. The second section was a table for prescription of antibiotics, in which respondents filled in the data on prescribed antibiotics for each patient. The dentists recorded the patient's age, gender, the name of antibiotics, dosage, frequency, duration of therapy (days), state (diagnosis), and the reason for prescribing antibiotics. The conditions for which the antibiotics were prescribed were as follows: acute ulcerative gingivitis, endodontic or periodontal abscess, dry socket, pericoronitis, chronic periodontitis, pain of unknown aetiology, after extraction, preoperatively, trauma, implant placement, periimplantitis, pulpitis, and direct pulp capping.

The reasons for prescribing antibiotics were listed as follows: definite clinical indications; "just in case"; the uncertainty about the diagnosis; prophylaxis, rheumatic fever, bacterial endocarditis, dental implant, etc.; patient's expectation; unavailability of dental services (e.g. at weekend); short term (e.g. insufficient time for the opening of the tooth); ailing patient; placebo. If the state or reason was not listed in the table, the respondents were asked to write them down.

\section{Statistical Analysis of Data}

The level of statistical significance was determined at $\mathrm{p}<0.05$, all confidence intervals were $95 \%$. In all cases, two-tailed tests of statistical significance were used. Normality of distribution was verified using Shapiro-Wilk test in case where the sub-samples were smaller than $n=30$, and Kolmogorov Smirnov test for larger ones. Bearing in mind the fact that in most cases statistically significant deviations from normal distribution existed, dispersion median and interquartile ranges were used as measures of central tendency. In addition, depending on the type of data, statistical significance was tested by Fisher exact test, X test, Mann-Whitney U test and Spearman's rank correlation. Analysis was performed using a statistical software package SPSS 17.0 (SPSS Inc., Chicago, IL, USA).

\section{RESULTS}

The total number of respondents was 110 dentists, 37 (33.6\%) males and $73(66.4 \%)$ females, with the median (interquartile range) age 48 (37.0 to 57.3). There were 27 (24.6\%) certified specialists in the total number of respondents. The prevalence of individual specialization was as follows: periodontics $2(1.81 \%)$, paediatric and preventive dentistry $12(10.9 \%)$, prosthodontics 7 (6.3\%), dental pathology and oral medicine $2(1.81 \%)$, surgery $3(2.7 \%)$, oral pathology $1(0.9 \%)$. The majority of subjects -74 $(67.3 \%)$ were in the public health care system, having a contract with public health insurance institute (The Croatian Health Insurance Institute - CHII).

Fifty $(45.5 \%)$ doctors of dental medicine attended seminars with the theme of prescribing antibiotics in the last two years.

In the first part of the study, in which doctors recorded the most frequently prescribed antibiotics (Table 1), the doctors' age was significantly associated with the statement that metronidazol was one of the most commonly prescribed antibiotics $\left(\chi^{2}=15.08\right.$, $\mathrm{df}=2, \mathrm{p}=0.001$, contingency coefficient $\mathrm{C}=0.37$ ), as claimed by younger doctors. Statement of the most frequently prescribed antibiotics was not significantly different for doctors employed in different types of offices (private or public health practice): penicillins $\left(\chi^{2}=0.91, \mathrm{df}=2, \mathrm{p}=0.633\right)$, other antibiotics $\left(\chi^{2}=1.42\right.$, $\mathrm{df}=2 ; \mathrm{p}=0.491)$, cephalosporins $\left(\chi^{2}=1.61, \mathrm{df}=2, \mathrm{p}=0.447\right)$.

A statistically significant difference was observed between specialists and general dental practitioners (GDPs) in the proportion of doctors who claimed that the most commonly used antibiotics were amoxicillin and clavulanic acid in a fixed combination (Fisher's exact test, $\mathrm{p}=0.001, \Phi=0.39$ ) and amoxicillin (Fisher's exact test, $\mathrm{p}=0.012, \Phi=0.28$ ). Among specialists, amoxicillin was 
Table 1. Self reported prescription and actually prescribed antibiotics $(n=1,476$; without data $=24(1.6 \%)$; sample size $n=1,500)$

\begin{tabular}{|c|c|c|c|c|c|}
\hline & \multirow{2}{*}{$\begin{array}{l}\text { Self reported most } \\
\text { frequently prescribed } \\
\text { antibiotics (\%) }\end{array}$} & \multicolumn{4}{|c|}{ Antibiotics prescribed during survey } \\
\hline & & $\begin{array}{c}\text { Number } \\
\text { of prescriptions }\end{array}$ & $\begin{array}{l}\text { Doctors prescribing } \\
\text { antibiotic }(\%)\end{array}$ & $95 \% \mathrm{Cl}$ & All medications (\%) \\
\hline Amoxicillin and clavulanic acid & 46.6 & 885 & 60.0 & $57.5-62.5$ & 57.6 \\
\hline Clindamycin & 17.7 & 218 & 14.8 & $13.0-16.6$ & 14.2 \\
\hline Metronidazole & 16.6 & 170 & 11.5 & $9.9-13.1$ & 11.1 \\
\hline Amoxicillin & 13.5 & 185 & 12.5 & $10.8-14.2$ & 12.0 \\
\hline Cephalexin & 4.1 & 59 & 4.0 & $3.0-4.5$ & 3.8 \\
\hline Azithromycin & 1.0 & 18 & 1.2 & $0.6-1.8$ & 1.2 \\
\hline Cefuroxime & 0.5 & 2 & 0.1 & $0.0-0.3$ & 0.1 \\
\hline Total & 100.0 & n.a. & n.a. & n.a. & 100.0 \\
\hline
\end{tabular}

$95 \% \mathrm{Cl}=95$ percent confidence interval, the percentage of patients who had been prescribed some medication

$\%$ of all medications = proportion of each drug in all prescribed medications

Table 2. Diagnoses for which antibiotics were prescribed ( $n=1,487$; missing data 13 (0.9\%); sample size $n=1,500)$

\begin{tabular}{|c|c|c|c|}
\hline & $\mathrm{n}$ & Valid cases $(\%)$ & $95 \% \mathrm{Cl}$ \\
\hline Periapical or periodontal abscess & 655 & 44.05 & $41.7-46.7$ \\
\hline Chronic periodontitis & 152 & 10.22 & $8.8-11.8$ \\
\hline After extraction & 143 & 9.62 & $8.1-11.1$ \\
\hline Pulpitis & 110 & 7.40 & $6.1-8.7$ \\
\hline Implant placement & 89 & 5.99 & $4.8-7.2$ \\
\hline Acute ulcerative gingivitis & 85 & 5.72 & $4.6-7.0$ \\
\hline Pericoronitis & 69 & 4.64 & $3.6-5.8$ \\
\hline Preoperatively & 59 & 3.97 & $3.0-5.0$ \\
\hline Acute inflammation & 36 & 2.42 & $1.6-3.2$ \\
\hline Dry socket & 23 & 1.55 & $0.6-2.2$ \\
\hline Pain of unknown aetiology & 19 & 1.28 & $0.7-1.9$ \\
\hline Trauma & 11 & 0.74 & $0.2-1.1$ \\
\hline Aggressive periodontitis & 11 & 0.74 & $0.2-1.1$ \\
\hline Periimplantitis & 5 & 0.34 & $0.0-0.6$ \\
\hline Gangrene & 4 & 0.27 & $0.0-0.6$ \\
\hline Chronic inflammation of the apical periodontal tissue & 4 & 0.27 & $0.0-0.6$ \\
\hline Caries & 4 & 0.27 & $0.0-0.6$ \\
\hline Direct pulp capping & 3 & 0.20 & $0.0-0.4$ \\
\hline Inflammation of the sublingual gland & 2 & 0.13 & $0.0-0.3$ \\
\hline Radicular cyst & 1 & 0.07 & $0.0-0.3$ \\
\hline Submandibular abscess & 1 & 0.07 & $0.0-0.3$ \\
\hline Fractured tooth & 1 & 0.07 & $0.0-0.3$ \\
\hline
\end{tabular}

$95 \% \mathrm{Cl}=95$ percent confidence interval, the percentage of patients with a particular diagnoses

one of the most commonly used antibiotic for $11 / 24$ (45.8\%), and among GDPs 13/73 (17.8\%). The fixed combination of amoxicillin with clavulanic acid was more commonly prescribed by GDPs $71 / 73(97.3 \%)$ than by specialists $17 / 24(70.8 \%)$.

In the second part of the study in which doctors followed the procedure of prescribing antibiotics for two months, it was observed that they prescribed antibiotics for 1,500 out of 35,714 (4.2\%) patients, $690(46 \%)$ males and 810 (54\%) females. The median (interquartile range) age of patients was 43 (29.8 to 58). The difference in median age of patients between males and females was not statistically significant (Mann-Whitney $\mathrm{U}=249 / 428, \mathrm{Z}=-1.51, \mathrm{p}=0.130$ ). One doctor, on average, followed 14 patients for whom he prescribed antibiotics. Doctors in public health service, on average, recorded prescribing antibiotics for 15 and doctors from private practices for 11 patients. The most common diagnosis for which doctors prescribed antibiotics was periapical or periodontal abscess (44\%) (Table 2).

The reasons for prescribing antibiotics are shown in Table 3 , while the reasons for prescribing antibiotics by diagnosis are shown in Table 4. During that period, the most often prescribed 
Table 3. Reasons for prescribing antibiotics

\begin{tabular}{|l|c|c|}
\hline & $\mathbf{n}$ & $\%$ \\
\hline Definite clinical indication & 954 & 71.2 \\
\hline $\begin{array}{l}\text { Prophylaxis, rheumatic fever, bacterial endo- } \\
\text { carditis, dental implant, etc. }\end{array}$ & 177 & 13.2 \\
\hline Ailing patient & 117 & 8.7 \\
\hline In any case, uncertainty about the diagnoses & 29 & 2.2 \\
\hline Unavailability of dental services & 22 & 1.6 \\
\hline Recommendation of specialist & 17 & 1.3 \\
\hline Patient's expectations & 16 & 1.2 \\
\hline Placebo & 4 & 0.3 \\
\hline Short term & 3 & 0.2 \\
\hline Trismus and swelling & 1 & 0.1 \\
\hline Total & 1,340 & 100.0 \\
\hline
\end{tabular}

antibiotics were penicillins. Out of 1,500 patients who were prescribed antibiotics, 1,070 (72.5\%) received antibiotics from penicillin pharmacological-therapy group (ATCJ01). The share of certain antibiotics prescribed in relation to the diagnosis is shown in Figure 1.

Daily doses of prescribed antibiotics are shown in Table 5. The antibiotic therapy usually lasted for 7 days (median 7 , interquartile range 5-8).

\section{DISCUSSION}

The Republic of Croatia is highly ranked in antibiotic outpatient use among European countries (13). The percentage of doctors of dental medicine accounts for $7.41 \%$ of the overall consumption of antibiotics in Croatia, while the usage of these

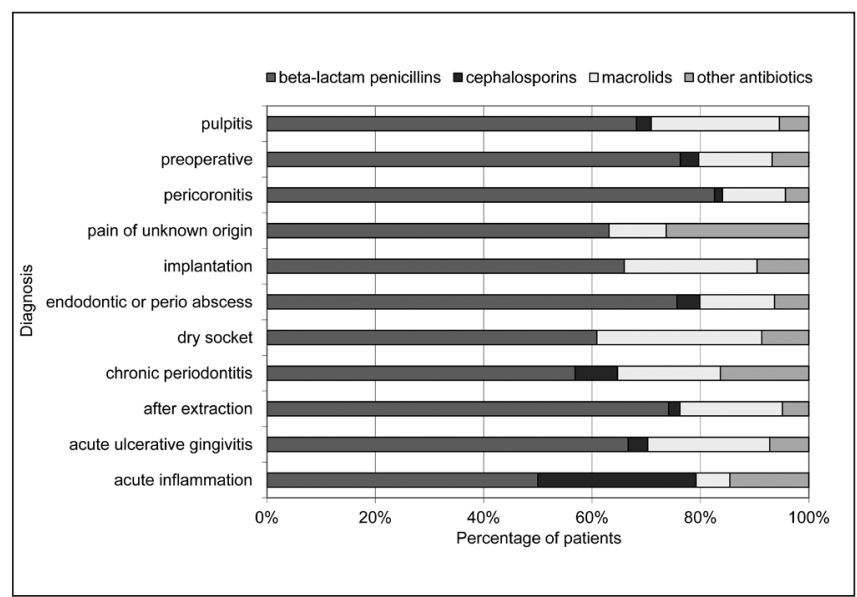

Fig. 1. The share of pharmaco-therapeutic subclasses in all antibiotics prescribed for particular indication $(n=1,482$; without data $18 / 1,500-1.2 \%)$.

drugs in hospitals is about $10 \%$ (14). Research performed in other countries showed that there is a general trend towards overprescribing $(6,10,15-18)$ of antibiotics in dental community, which can significantly contribute to the worldwide problem of bacterial resistance. Although the development of bacterial resistance is not in a simple quantitative relationship with the volume of the drug, the reduction in antibiotic resistance can only occur after a significant reduction in antibiotic use (7). Considering that, antimicrobial drugs should not be used for mild infections without strict indications. In order to reduce or to improve prescription of antibiotics in dentistry, it is important to find out the pattern of prescription, including diagnosis, reasons for prescription, dosage and duration of the therapy in the target group of therapists. Knowing these factors, along with pharmacokinetic and pharmacodynamic aspects of antibiotics, microbiology of the oral conditions requiring antibiotics, the prevalence of resistant bacterial strains

Table 4. Reasons for prescribing antibiotics by diagnosis

\begin{tabular}{|c|c|c|c|c|c|c|c|c|c|c|c|}
\hline & 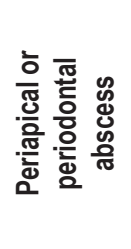 & .를 & 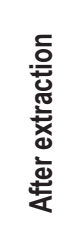 & $\frac{\text { 告 }}{\frac{\text { 음 }}{\bar{a}}}$ & 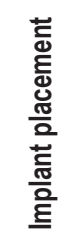 & 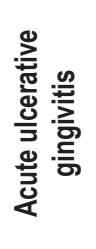 & 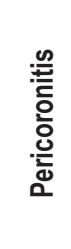 & 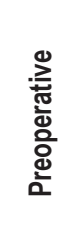 & 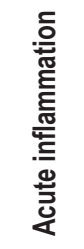 & 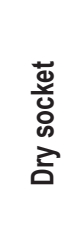 & 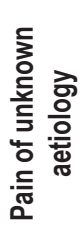 \\
\hline Number of patients & 655 & 152 & 143 & 110 & 89 & 85 & 69 & 59 & 36 & 23 & 19 \\
\hline Definite clinical indication & $85 \%$ & $76 \%$ & $56 \%$ & $46 \%$ & $22 \%$ & $84 \%$ & $81 \%$ & $23 \%$ & $100 \%$ & $73 \%$ & $11 \%$ \\
\hline $\begin{array}{l}\text { In any case, uncertainty about the } \\
\text { diagnoses }\end{array}$ & $2 \%$ & $1 \%$ & $4 \%$ & $0 \%$ & $0 \%$ & $1 \%$ & $2 \%$ & $4 \%$ & $0 \%$ & $0 \%$ & $32 \%$ \\
\hline $\begin{array}{l}\text { Prophylaxis, rheumatic fever, bacte- } \\
\text { rial endocarditis, dental implant, etc. }\end{array}$ & $3 \%$ & $7 \%$ & $18 \%$ & $44 \%$ & $77 \%$ & $3 \%$ & $3 \%$ & $67 \%$ & $0 \%$ & $0 \%$ & $11 \%$ \\
\hline Patient's expectations & $1 \%$ & $1 \%$ & $3 \%$ & $0 \%$ & $0 \%$ & $2 \%$ & $0 \%$ & $0 \%$ & $0 \%$ & $0 \%$ & $21 \%$ \\
\hline Unavailability of dental services & $2 \%$ & $2 \%$ & $1 \%$ & $2 \%$ & $0 \%$ & $0 \%$ & $1 \%$ & $0 \%$ & $0 \%$ & $0 \%$ & $4 \%$ \\
\hline Lack of time & $0 \%$ & $0 \%$ & $0 \%$ & $2 \%$ & $0 \%$ & $0 \%$ & $0 \%$ & $0 \%$ & $0 \%$ & $0 \%$ & $0 \%$ \\
\hline Ailing patient (pain) & $6 \%$ & $12 \%$ & $13 \%$ & $4 \%$ & $1 \%$ & $4 \%$ & $13 \%$ & $4 \%$ & $0 \%$ & $18 \%$ & $21 \%$ \\
\hline Placebo & $0 \%$ & $0 \%$ & $0 \%$ & $2 \%$ & $0 \%$ & $1 \%$ & $0 \%$ & $0 \%$ & $0 \%$ & $5 \%$ & $0 \%$ \\
\hline Recommendation of specialist & $1 \%$ & $1 \%$ & $4 \%$ & $0 \%$ & $0 \%$ & $5 \%$ & $0 \%$ & $2 \%$ & $0 \%$ & $4 \%$ & $0 \%$ \\
\hline Trismus and swelling & $0 \%$ & $0 \%$ & $1 \%$ & $0 \%$ & $0 \%$ & $0 \%$ & $0 \%$ & $0 \%$ & $0 \%$ & $0 \%$ & $0 \%$ \\
\hline
\end{tabular}


Table 5. Daily dose in $\mathrm{mg}$ and duration of the therapy

\begin{tabular}{|l|c|c|c|c|c|c|c|c|c|c|c|c|}
\hline & \multicolumn{9}{|c|}{ Daily doses (mg) } & \multicolumn{5}{c|}{ Duration of therapy (days) } \\
\cline { 2 - 15 } & $\mathbf{n}$ & AM & SD & Median & IQR & min-max & AM & SD & Median & IQR & min-max \\
\hline All antibiotics (whole sample) & 1,476 & 1,200 & 594 & 2,000 & $1,600-2,400$ & $8-8,000$ & 6.4 & 1.56 & 7 & $5-8$ & $1-15$ \\
\hline Pharmacological and therapeutic subgroups \\
\hline Beta-lactam penicillins & 1,070 & 1,873 & 406 & 2,000 & $2,000-2,000$ & $15-8,000$ & 6.7 & 1.21 & 7 & $7-7$ & $1-14$ \\
\hline Macrolides and lincosamides & 236 & 812 & 280 & 900 & $600-1,200$ & $300-2,000$ & 5.1 & 1.74 & 7 & $6-8$ & $1-15$ \\
\hline Other antibiotics & 170 & 1,441 & 315 & 1,200 & $800-1,600$ & $250-3,000$ & 6.6 & 2.21 & 7 & $5-8$ & $3-15$ \\
\hline Cephalosporins & 61 & 1,246 & 510 & 1,000 & $688-1,312$ & $150-2,400$ & 5.7 & 1.93 & 5 & $4-7$ & $4-10$ \\
\hline Certain medications & & & & & & & \\
\hline Amoxicillin and clavulanic acid & 885 & 1,912 & 384 & 2,000 & $2,000-2,000$ & $8-4,000$ & 6.9 & 0.91 & 7 & $7-7$ & $1-14$ \\
\hline Metronidazole & 170 & 1,414 & 448 & 1,200 & $800-1,600$ & $250-3,000$ & 6.6 & 2.21 & 7 & $5-7$ & $3-15$ \\
\hline Clindamycin & 218 & 824 & 261 & 900 & $900-900$ & $300-2,000$ & 5.3 & 1.69 & 5 & $5-6$ & $1-15$ \\
\hline Amoxicillin & 185 & 1,553 & 670 & 1,500 & $1,500-1,500$ & $140-8,000$ & 5.7 & 1.81 & 5 & $5-7$ & $1-14$ \\
\hline Cephalexin & 59 & 1,268 & 491 & 1,000 & $562-1,438$ & $500-2,400$ & 5.8 & 1.95 & 5 & $4-7$ & $4-10$ \\
\hline Azithromycin & 18 & 676 & 431 & 500 & $500-500$ & $500-2,000$ & 3.2 & 0.97 & 3 & $3-3$ & $3-7$ \\
\hline Cefuroxime & 2 & 825 & 954 & 825 & n.a. & $150-1,500$ & 5.5 & 2.12 & 6 & $4-7$ & $4-7$ \\
\hline
\end{tabular}

$\mathrm{AM}=$ arithmetic mean, $\mathrm{SD}=$ standard deviation, $\mathrm{IQR}=$ interquartile range, $\min =$ minimum dose, max = maximum dose

etc., could be helpful in setting up the educational programmes that would help to change prescribing habits in dentistry and thus lessening the impact of antibiotic resistance in the future.

Out of 1,500 patients who received antibiotics, 655 (44.2\%) were prescribed antibiotics because of periapical or periodontal abscess, which is similar to the results obtained by Palmer et al. (12). The next most common diagnosis for which antibiotics were prescribed were chronic periodontitis in 152 patients (10.3\%), after extraction in 143 patients $(9.6 \%)$, pulpitis in 110 patients (7.4\%), although according to Tong et al. (4) and Steed et al. (9), these were not indications for prescribing antibiotics. It has been generally accepted that antibiotic therapy is inappropriate as a primary therapy of pulpitis (19), which, in its nature, is an inflammatory process and only the local therapy can relieve pain and eliminate the infection (20). A Cochrane systematic review provided evidence that there is no significant difference in pain relief for patient with untreated irreversible pulpitis who did or did not receive antibiotics (21). Implant placement does not carry a significant risk of developing bacteraemia. Therefore, the use of antibiotic prophylaxis for implant placement for the prevention of focal infection in all patients is questionable $(22,23)$. Also, the success rate of implant placement was similar when antibiotics were not administrated or when they were administrated preoperatively and/or postoperatively (24). The acute ulcerative gingivitis was an indication for prescribing antibiotics, which were in our study prescribed to 86 patients $(5.8 \%)$, as well as pericoronitis, for which antibiotics were prescribed to 69 patients $(4.7 \%)$, which complies with the results of similar studies $(2,12)$. The antibiotics were preoperatively given to 59 patients $(4.0 \%)$, the use was associated with prophylaxis of bacterial endocarditis, rheumatic fever etc. Currently, there are insufficient data on whether antibiotic prophylaxis is effective or ineffective in preventing bacterial endocarditis in high-risk patients undergoing dental procedures such as root canal treatment $(23,25)$. Some authors claim that the risk of inappropriate use of antibiotics and expanding antibiotic resistance is much more important than their possible positive ef- fects (26), although the recommendations for their use in high-risk patients are still in effect (27). For the diagnosis of dry socket, antibiotics were prescribed to 23 patients $(1.6 \%)$. With this diagnosis, a systemic antibiotic prophylaxis should be reserved only for immunosuppressed patients (28). For the diagnosis of pain of unknown aetiology, antibiotics were prescribed to 19 patients (1.3\%). The most common reasons for prescribing antibiotics for this diagnosis were: "just in case" (32\%), "patient's expectation" $(21 \%)$ and "ailing patient" (21\%). A large proportion of these reasons points to the need of finding the cause, and not prescribing antibiotics without firm clinical indications.

If all the reasons why antibiotics were prescribed are taken into the account, the most common were listed as: "clinical indications", "prophylaxis, rheumatic fever, bacterial endocarditis, and other" and, surprisingly, "ailing patient", "just in case, uncertainty in diagnosis", "unavailability of dental services". The reasons such as "painful patient", "just in case, uncertainty about the diagnosis" and "the unavailability of dental services" encompass $12.5 \%$ of all the reasons for prescribing antibiotics, which points to the excessive use of antibiotics when they are not indicated. The finding that to $44 \%$ of patients with pulpitis diagnosis, antibiotics were prescribed for prophylactic reasons (rheumatic fever, bacterial endocarditis, implant surgery, etc.) confirms the previous assumption that antibiotics were overprescribed in cases where antibiotic therapy was not beneficial at all.

In some similar studies, the most frequently prescribed antibiotic among dentists was amoxicillin $(7,11,29)$, this study has shown that the most commonly prescribed antibiotic was a combination of amoxicillin and clavulanic acid. This antibiotic was prescribed to $885(60 \%)$ patients, which amounts to $57.6 \%$ of all prescribed antibiotics. The combination of amoxicillin and clavulanic acid and amoxicillin alone have similar indications. In addition to the spectrum of amoxicillin, the combination of amoxicillin and clavulanic acid is effective against Klebsiella and a wide range of anaerobes. In the initial phase of odontogenic infections the predominant microorganisms are gram-positive cocci 
- facultative anaerobes ( $85 \%$ ). An advanced stage of odontogenic inflammation is characterized by abscess formation wherein the strict anaerobes such as gram-negative $(50 \%)$ and gram-positive cocci $(30 \%)$ play the main role. Knowing the cause of infection, the therapist could empirically prescribe antibiotics before microbiological findings and antibiograms, which are rarely performed in dentistry. When there is no improvement after the application of amoxicillin in the next two days after local dental treatment, metronidazole should be additionally prescribed. This drug shows bactericidal activity against gram-negative anaerobic bacteria, and because of its narrow spectrum poses less risk for the development of bacterial resistance (9).

The second most commonly prescribed antibiotic among examined Croatian dentists is clindamycin. It was prescribed to 218 ( $14.8 \%$ ) patients, amounting to $14.2 \%$ of all prescribed antibiotics. One of the reasons why clindamycin is so frequently used, apart from its excellent antibacterial effectiveness and pharmacodynamic properties, is because it is recommended in cases where penicillin is contraindicated, such as the prevention of bacterial endocarditis in high-risk patients allergic to penicillin (30).

Metronidazole was prescribed to $170(11.5 \%)$ patients, amounting to $11.1 \%$ of the total number of prescribed antibiotics. The indication for metronidazole is infection caused by obligate anaerobes, but it is ineffective against aerobes. Therefore, it should be used in conjunction with other chemotherapeutics for oral infections, if previously prescribed antibiotic did not lead to improvement or clinical signs are too severe (10). Cephalexin was prescribed to $59(4 \%)$ patients, i.e. $3.8 \%$ of all prescribed antibiotics. Azithromycin was prescribed to $18(2.1 \%)$ patients. It is antibiotic that is effective against a broad spectrum of microorganisms found in the mouth. A simple and brief therapy of azithromycin can be helpful to improve the patient's cooperation (31).

The dosage and duration of antibiotic therapy of Croatian dentists is in accordance with the previous recommendation (32). Recently, a short-course antibiotic administration in optimal doses during 2 or 3 days for the treatment of acute dento-alveolar infections was advocated by some authors because of its efficacy (33). With reasoning that resistance is acquired via transposable elements when antibiotics are used in sub-therapeutic doses or during a prolonged therapy (2), there is a need for further investigation of such short antibiotic prescription regimen.

Antibiotic therapy is of great importance in medicine and dentistry. We depend on its effectiveness as clinicians and as members of the population. Dentistry should strive to achieve full compliance with the recommendations related to antibiotic prophylaxis and understanding the proper use of antibiotics in the profession. Conscientious use of antibiotics is imperative for all clinicians, including dentists, especially considering the rapid development of antibacterial resistance and the alarming consequences of this trend (34).

\section{CONCLUSION}

Although the results of this study show that most respondents prescribed antibiotics in accordance with the recommendations on the type of antibiotic, dose and duration of therapy, there was a discrepancy in diagnoses and reasons for which antibiotics were prescribed. Reasons for dentists to prescribe antibiotics inappro- priately are not obvious. However, some of the possible explanations can be insufficient understanding of pathological processes in the pulp and periapical area and lack of knowledge about basic indications for the effective use of antibiotics. Antibiotics are a precious medicine for the treatment of orofacial infections and their responsible use should be of the utmost importance. The increase in bacterial resistance is well documented and serious global problem, and inadequate use of antibiotics in dental medicine can aggravate it. Antibiotic prescription in accordance with the recent studies is taught in the Schools of Dental Medicine in Croatia. However, it is important to emphasize that there is a need for regular professional courses to broaden knowledge about antibiotic spectrum and mechanism of action, and hence the indications for their use. By adherence to recent antibiotic regime recommendations, overprescription of antibiotic therapy and resulting complications could be ameliorated. Also, national guidelines on antibiotic regimens in dental medicine should be developed in order to reduce antibiotic prescription.

\section{Conflict of Interests}

None declared

\section{Ethical Approval}

Ethical approval was received from the Ethics Committee of the Zagreb University School of Dental Medicine (No. 05-PA-26-10/10 point: 3.5).

\section{Funding}

This work is a part of the project 065-0650445-0434 supported by the Ministry of Science, Education and Sports of the Republic of Croatia.

\section{Declaration of Authorship}

MP, IP and MR performed literature search, research organization and coordination, data collection, data organization and wrote the manuscript. JM performed the part of statistical analysis, PS performed manuscript review, GPM performed data interpretation and manuscript review, SJK performed the study design.

\section{REFERENCES}

1. British Infection Association. Management of infection guidance for primary care for consultation and local adaptation [Internet]. [cited 2013 Jan 31]. Available from: http://www.hpa.org.uk/webc/hpawebfile/ hpaweb_c/1194947333801.

2. Dar-Odeh NS, Abu-Hammad OA, Al-Omiri MK, Khraisat AS, Shehabi AA. Antibiotic prescribing practices by dentists: a review. Ther Clin Risk Manag. 2010 Jul 21;6:301-6.

3. Goodchild JH, Donaldson M. Appropriate antibiotic prescribing for the general dentist. Gen Dent. 2009 Nov-Dec;57(6):626-34.

4. Tong DC, Rothwell BR. Antibiotic prophylaxis in dentistry: a review and practice recommendations. J Am Dent Assoc. 2000 Mar;131(3):366-74.

5. Poveda Roda R, Bagan JV, Sanchis Bielsa JM, Carbonell Pastor E. Antibiotic use in dental practice. A review. Med Oral Patol Oral Cir Bucal. 2007 May 1;12(3):E186-92.

6. Epstein JB, Chong S, Le ND. A survey of antibiotic use in dentistry. J Am Dent Assoc. 2000 Nov;131(11):1600-9.

7. Sweeney LC, Dave J, Chambers PA, Heritage J. Antibiotic resistance in general dental practice - a cause for concern? J Antimicrob Chemother. 2004 Apr;53(4):567-76.

8. Palmer NO, Martin MV, Pealing R, Ireland RS, Roy K, Smith A, et al. Antibiotic prescribing knowledge of National Health Service general dental practitioners in England and Scotland. J Antimicrob Chemother. $2001 \mathrm{Feb} ; 47(2): 233-7$.

9. Steed M, Gibson J. An audit of antibiotic prescribing in general dental practice. Prim Dent Care. 1997 May;4(2):66-70. 
10. Segura-Egea JJ, Velasco-Ortega E, Torres-Lagares D, Velasco-Ponferrada MC, Monsalve-Guil L, Llamas-Carreras JM. Pattern of antibiotic prescription in the management of endodontic infections amongst Spanish oral surgeons. Int Endod J. 2010 Apr;43(4):342-50.

11. Salako NO, Rotimi VO, Adib SM, Al-Mutawa S. Pattern of antibiotic prescription in the management of oral diseases among dentists in Kuwait. J Dent. 2004 Sep;32(7):503-9.

12. Palmer NA, Dailey YM, Martin MV. Can audit improve antibiotic prescribing in general dental practice? Br Dent J. 2001 Sep 8;191(5):253-5

13. Ferech M, Coenen S, Malhotra-Kumar S, Dvorakova K, Hendrickx E, Suetens C, et al.; ESAC Project Group. European Surveillance of Antimicrobial Consumption (ESAC): outpatient antibiotic use in Europe. J Antimicrob Chemother. 2006 Aug;58(2):401-7.

14. Bebek B. Contribution of doctor of dental medicine in national outpatients antibiotic consumption in the Republic of Croatia [dissertation]. Zagreb: University of Zagreb; 2012.

15. Lauber C, Lalh SS, Grace M, Smith MH, MacDougall K, West P, et al. Antibiotic prophylaxis practices in dentistry: a survey of dentists and physicians. J Can Dent Assoc. 2007 Apr;73(3):245.

16. Palmer NO, Martin MV, Pealing R, Ireland RS. An analysis of antibiotic prescriptions from general dental practitioners in England. J Antimicrob Chemother. 2000 Dec;46(6):1033-5.

17. Jaunay T, Sambrook P, Goss A. Antibiotic prescribing practices by South Australian general dental practitioners. Aust Dent J. 2000 Sep;45(3):17986.

18. Zadik Y, Levin L. Clinical decision making in restorative dentistry, endodontics, and antibiotic prescription. J Dent Educ. 2008 Jan;72(1):81-6.

19. Dailey YM, Martin MV. Are antibiotics being used appropriately for emergency dental treatment? Br Dent J. 2001 Oct 13;191(7):391-3

20. Piñeiro A, Tomás I, Blanco J, Alvarez M, Seoane J, Diz P. Bacteraemia following dental implants' placement. Clin Oral Implants Res. 2010 Sep;21(9):913-8.

21. Keenan JV, Farman AG, Fedorowicz Z, Newton JT. Antibiotic use for irreversible pulpitis. Cochrane Database Syst Rev. 2005 Apr 18;(2):CD004969. Review. Update in: Cochrane Database Syst Rev. 2013;12:CD004969.

22. Brincat M, Savarrio L, Saunders W. Endodontics and infective endocarditis - is antimicrobial chemoprophylaxis required? Int Endod J. 2006 Sep;39(9):671-82.
23. Dinsbach NA. Antibiotics in dentistry: Bacteremia, antibiotic prophylaxis, and antibiotic misuse. Gen Dent. 2012 May-Jun;60(3):200-7.

24. Ahmad N, Saad N. Effects of antibiotics on dental implants: a review. J Clin Med Res. 2012 Feb;4(1):1-6.

25. Carmona IT, Diz Dios P, Scully C. An update on the controversies in bacterial endocarditis of oral origin. Oral Surg Oral Med Oral Pathol Oral Radiol Endod. 2002 Jun;93(6):660-70.

26. Lockhart PB, Loven B, Brennan MT, Fox PC. The evidence base for the efficacy of antibiotic prophylaxis in dental practice. J Am Dent Assoc. 2007 Apr;138(4):458-74

27. Noroozi AR, Philbert RF. Modern concepts in understanding and management of the "dry socket" syndrome: comprehensive review of the literature. Oral Surg Oral Med Oral Pathol Oral Radiol Endod. 2009 Jan;107(1):30-5.

28. Roy KM, Bagg J. Antibiotic prescribing by general dental practitioners in the Greater Glasgow Health Board, Scotland. Br Dent J. 2000 Jun 24;188(12):674-6.

29. Al-Haroni M. Bacterial resistance and the dental professionals' role to halt the problem. J Dent. 2008 Feb;36(2):95-103.

30. Palmer NA, Pealing R, Ireland RS, Martin MV. A study of prophylactic antibiotic prescribing in National Health Service general dental practice in England. Br Dent J. 2000 Jul 8;189(1):43-6.

31. Addy LD, Martin MV. Azithromycin and dentistry - a useful agent? Br Dent J. 2004 Aug 14;197(3):141-3.

32. HALMED. National Agency for Medicinal Products and Medical Devices of Republic of Croatia [Internet]. Zagreb: Agency for Medicinal Products and Medical Devices; c2007-15 [cited 2015 Jun 4]. Available from: http:// www.halmed.hr/?ln=hr\&w=lijekovi\&d=pacijenti.

33. Ellison SJ. An outcome audit of three day antimicrobial prescribing for the acute dentoalveolar abscess. Br Dent J. 2011 Dec 23;211(12):591-4.

34. Gaetti-Jardim EC, Marqueti AC, Faverani LP, Gaetti-Jardim E Jr. Antimicrobial resistance of aerobes and facultative anaerobes isolated from the oral cavity. J Appl Oral Sci. 2010 Dec;18(6):551-9.

Received November 14, 2013 Accepted in revised form May 11, 2015 